\title{
Competência em Informação e Cultura Organizacional: fatores fundamentais na construção da memória organizacional
}

\author{
Information Literacy and Organizational Culture: key elements to construct organizational \\ memory
}

Selma Letícia Capinzaiki Ottonicar Mestranda em Ciência da Informação no Programa de Pós-Graduação em Ciência da Informação da Universidade Estadual Paulista "Júlio de Mesquita Filho" - UNESP. E-mail: selma.leticia@hotmail.com

Luis Fernando Condutta Mestrando em Ciência da Informação no Programa de Pós-Graduação em Ciência da Informação da Universidade Estadual Paulista "Júlio de Mesquita Filho" - UNESP. E-mail: fernando.condutta@gmail.com

\begin{abstract}
Marcia Cristina de Carvalho Pazin Vitoriano
Doutora em História Social pela Universidade de São Paulo.

Docente do Departamento de Ciência da Informação da Universidade Estadual Paulista "Júlio de Mesquita

Filho" - UNESP.

E-mail: marciapazin@marilia.unesp.br
\end{abstract}

\begin{abstract}
Resumo
As organizações produzem e absorvem informações e conhecimentos em todas as suas atividades e por isso adotam a memória organizacional como estratégia para o pleno desenvolvimento da gestão da informação e do conhecimento. Desse modo o trabalho possui o seguinte problema de pesquisa: Qual a influência dos elementos da cultura organizacional e da competência em informação para a construção e o uso da memória organizacional? Portando a pesquisa tem como objetivo refletir sobre a relação dos elementos da cultura organizacional e a competência em informação para a criação e o uso da memória e se justifica pelo fato de que quando a cultura organizacional encontra-se voltada para a competência em informação essa se torna um fator chave para a construção do conhecimento. Assim, os procedimentos metodológicos são formados por uma revisão bibliográfica sobre memória organizacional, competência em informação e os elementos da cultura organizacional propostos por Schein (2009), como subsídios para a construção de um quadro que correlacione os temas no contexto das organizações. Desse modo, a cultura organizacional que valoriza a competência em informação contribui com a construção estruturada da memória. Os resultados indicam que a construção da memória organizacional depende dos elementos da cultura organizacional capazes de influenciar a competência em informação do profissional e também do uso dessa memória pelos membros da organização.
\end{abstract}

Palavras-chave: Memória organizacional. Competência em informação. Cultura organizacional.

\begin{abstract}
The organizations produce and absorb information and knowledge in all activities and because of that they adopt organizational memory as a strategy to develop information and knowledge management. So this paper has the following question as a research problem: what are the influences of the elements of organizational culture and information literacy to create and develop organizational memory? This paper aims to explain the relation between the elements of organizational culture to create and use the organizational memory. This research is relevant because the organizational culture orientated to information literacy is a key factor to build knowledge. Thus the methodological procedures involve a bibliographical research about organizational memory, information literacy and the elements of organizational culture suggested by Schein (2009) as a subsidy to build a board connecting those themes in the organizational context. So, the culture that value information literacy contributes to memory, since professionals want to expand their abilities, capacities and knowledge to create and use the memory. The results indicate that the development of organizational memory depends on the elements of organizational culture which are capable of influence information literacy of professionals and also the use of that memory by the members of organization.
\end{abstract}

Keywords: Organizational memory. Information literacy. Organizational culture.

InCID: R. Ci. Inf. e Doc., Ribeirão Preto, v. 7, n. 1, p. 111-130, mar./ago. 2016.

DOI: 10.11606/issn.2178-2075.v7i1p111-130 
Competência em Informação e Cultura Organizacional: fatores fundamentais na construção da memória organizacional

\section{Introdução}

Ao longo dos anos, a sociedade sofreu transformações econômicas e sociais devido à evolução do conhecimento. Por meio da concorrência foi possível compreender que o conhecimento compartilhado estimula o desenvolvimento de serviços ou produtos (FARIA et al., 2012).

De acordo com Drucker (1998) o contexto altamente competitivo faz com que as empresas se voltem para o seu ambiente externo, observando as ameaças e oportunidades do mercado. $\mathrm{O}$ autor ainda destaca que em um ambiente concorrencial globalizado as organizações bem sucedidas utilizam a informação e o conhecimento como um capital de valor estratégico.

Nesse sentido é fundamental que a gestão do conhecimento seja aplicada na organização, a fim de estimular a explicitação e o armazenamento por meio do uso da memória organizacional (FARIA et al., 2012).

Porém todo esse montante de informações e conhecimentos disponíveis pode se perder com o passar do tempo. Para evitar isso, as organizações possuem uma ferramenta que sistematiza as informações a fim de que usuários possam ter acesso. Essa ferramenta é intitulada de memória organizacional e pode ser definida por Menezes (2006, p.31) como o "acervo de informação, conhecimento e práticas, agregados e retidos pela organização ao longo de sua existência, utilizados para o suporte às suas atividades, seus processos decisórios e para a preservação de seu capital intelectual, potencializando a gestão do conhecimento".

Um dos principais objetivos da memória organizacional é o de constituir mecanismos que permitam armazenar documentos com informações e conhecimentos que serão utilizados posteriormente pela organização. Além disso, a memória facilita a busca das informações porque estrutura o arcabouço documental, permitindo que os indivíduos se apropriem de conhecimentos passados, previamente selecionados e organizados para essa finalidade.

Cabe ao profissional da informação estruturar a memória organizacional de modo a atender as necessidades da organização, avaliando o período de armazenamento das informações, classificando os documentos que contribuem com a tomada de decisão e indicando dentre esses quais os que representam efetivamente conteúdo organizacional significativo. Para realizar essas ações o profissional da informação precisa conhecer a instituição de uma maneira holística, ou seja, entender a missão, visão, valores, compreender 
as diretrizes estabelecidas pelo planejamento estratégico, de modo a conhecer as necessidades de informação dos diferentes departamentos e áreas.

Neste contexto, compreender o valor de cada informação e ser capaz de identificar quais representam diferencial competitivo deve ser um dos objetivos dos gestores. Segundo as percepções de Peter Drucker, os executivos são competentes em manusear os computadores, contudo poucos são aqueles competentes em informação. Usar a tecnologia de informação e comunicação não é suficiente, sendo crucial saber identificar os problemas de informação, encontrar, avaliar, sintetizar e principalmente, fazer o uso efetivo dessa informação (EINSENBERG, 2008).

O trabalho do profissional da informação não é apenas o de "arrumar papéis", é um trabalho complexo e integrador, exigindo que o profissional tenha competência em informação para construir uma memória organizacional eficaz. Sendo assim, o presente artigo possui a seguinte questão como problema de pesquisa: Qual a influência dos elementos da cultura organizacional e da competência em informação para a construção e o uso da memória organizacional?

Portanto o trabalho tem como objetivo refletir sobre a relação dos elementos da cultura organizacional e a competência em informação para a criação e o uso da memória organizacional.

A pesquisa se justifica porque a competência em informação é um fator chave para a construção do conhecimento na organização e a cultura organizacional influencia os indivíduos a fazerem um melhor uso da memória organizacional. Além disso, o profissional da informação possui habilidades para desenvolver e manter essa memória, atendendo às necessidades da organização.

InCID: R. Ci. Inf. e Doc., Ribeirão Preto, v. 7, n. 1, p. 111-130, mar./ago. 2016. 
Competência em Informação e Cultura Organizacional: fatores fundamentais na construção da memória organizacional

\section{Procedimentos metodológicos}

O presente artigo foi desenvolvido com base em uma pesquisa bibliográfica, que se adéqua melhor aos temas inovadores, concordando Marconi e Lakatos (2006, p. 71) "[...] a pesquisa bibliográfica não é mera repetição do que foi dito ou escrito sobre certo assunto, mas propicia o exame de um tema sob novo enfoque ou abordagem, chegando a conclusões inovadoras".

A pesquisa bibliográfica é conveniente aos temas novos, uma vez que serve de suporte a outras pesquisas de cunho teórico e prático. De acordo com Gil (2008, p. 50): "é desenvolvida a partir de material já elaborado, constituído de livros e artigos científicos”.

$\mathrm{Na}$ construção da revisão teórica utilizaram-se conceitos advindos da arquivologia, biblioteconomia, educação, administração e gestão do conhecimento, caracterizando o trabalho como complexo, pois lida com ideias de diferentes áreas. Essa interdisciplinaridade é reforçada no campo da ciência da informação, por se utilizar dos conceitos de memória organizacional, cultura organizacional e competência em informação.

Posteriormente, foi construído um quadro relacionando a influência dos elementos da cultura organizacional, as capacidades e habilidades dos indivíduos estimuladas por tais elementos e o resultado dessa influência, que possibilita o uso eficaz da memória organizacional. Por fim, elencaram-se as capacidades e habilidades necessárias ao profissional da informação para construir essa memória de acordo com as necessidades informacionais da organização. Ressalta-se que o trabalho está direcionado tanto ao uso da memória organizacional pelos indivíduos quanto à competência do profissional da informação, responsável pela elaboração da memória nas organizações. 


\section{Memória organizacional, gestão da informação e do conhecimento}

Antes de discorrer sobre memória organizacional e gestão da informação e do conhecimento é relevante destacar os conceitos de dado, informação e conhecimento, uma vez que esses são os elementos essenciais que a compõem. Atualmente existem vários questionamentos e divergências em relação ao seu real significado, portanto, nesse trabalho optou-se pelos conceitos que se relacionam com o indivíduo, por considerarmos o ser humano como peça central na construção do conhecimento.

O dado, a informação e o conhecimento são elementos que se complementam e por isso, são de difícil conceituação. Além disso, cada área do conhecimento permite que sejam entendidos de uma maneira diferente o que, consequentemente, dificulta a consolidação de uma definição única. A fim de visualizar o papel de cada elemento, Davenport e Prusak (1998) desenvolveram uma tabela diferenciando cada elemento, conforme segue:

Tabela 1: Dado, Informação e Conhecimento

\begin{tabular}{|c|c|c|}
\hline Dado & Informação & Conhecimento \\
\hline $\begin{array}{c}\text { Simples observações sobre } \\
\text { o estado do mundo }\end{array}$ & $\begin{array}{l}\text { Dados dotados de } \\
\text { relevância e propósito }\end{array}$ & $\begin{array}{l}\text { Informação valiosa da } \\
\text { mente humana }\end{array}$ \\
\hline Facilmente estruturado & Requer unidade de análise & Inclui reflexão e síntese \\
\hline $\begin{array}{l}\text { Facilmente obtido por } \\
\text { máquinas }\end{array}$ & $\begin{array}{l}\text { Exige consenso em } \\
\text { relação ao significado }\end{array}$ & De difícil estruturação \\
\hline $\begin{array}{c}\text { Frequentemente } \\
\text { quantificado }\end{array}$ & $\begin{array}{l}\text { Exige, necessariamente, a } \\
\text { mediação humana. }\end{array}$ & $\begin{array}{c}\text { De difícil captura em } \\
\text { máquinas }\end{array}$ \\
\hline Facilmente transferível & & De difícil transferência \\
\hline
\end{tabular}

Fonte: Davenport (1998, p. 18)

Complementando, Setzer (1999, p. web) detalha:

Definimos dado como uma sequência de símbolos quantificados ou quantificáveis.
Portanto, um texto é um dado. De fato, as letras são símbolos quantificados, já que o
alfabeto por si só constitui uma base numérica. Também são dados imagens, sons e
animação, pois todos podem ser quantificados a ponto de alguém que entra em contato
com eles ter eventualmente dificuldade de distinguir a sua reprodução, a partir da
representação quantificada, com o original. É muito importante notar-se que qualquer
texto constitui um dado ou uma sequência de dados, mesmo que ele seja ininteligível
para o leitor.

Por meio da interferência humana, os dados são transformados em informações. Conforme afirma Logan (2012), etimologicamente, a palavra informação vem do latim por meio do francês unindo o termo "informar" que pode significar "dar forma à mente", com o sufixo "ção" que remete a uma ação; significando moldagem ou treinamento da mente. Foi 
Competência em Informação e Cultura Organizacional: fatores fundamentais na construção da memória organizacional

somente em meados do século XX que a informação adquiriu uma conotação de "algo" que pode ser compartilhado, armazenado, comunicado para um objeto inorgânico e o seu conceito foi interpretado como "uma quantidade definida matematicamente".

Em 1948, Claude Shannon foi um dos pioneiros a atribuir significado à palavra informação do ponto de vista da codificação do conteúdo. Segundo ele a informação é a mensagem lançada do emissor em direção ao receptor. Trabalhando no ambiente da tecnologia de telecomunicações, necessitava solucionar um problema: descobrir como codificar informações transmitidas de um emissor para um receptor, atribuindo à informação um valor numérico ou matemático baseado na probabilidade conceituada pela entropia de informação ou entropia de Shannon (LOGAN, 2012).

A teoria matemática de Claude Shannon delimita uma época em que se utilizava o conceito de informação voltado às suas dimensões semânticas e pragmáticas e redefinindo a palavra dentro do campo da engenharia. As definições de conhecimento e comunicação foram construídas, aparentemente, por uma peripécia linguística (CAPURRO, HJORLAND, 2007).

Poderíamos, então, considerar a informação como um conjunto de dados estruturados e organizados de modo a representar um conteúdo inteligível ao receptor, respondendo a uma questão previamente formulada. A informação depende, portanto, da recombinação de dados passíveis de serem utilizados para análise e interpretação de uma determinada situação.

Para complementar a temática 'informação' no ambiente organizacional, Choo (2011) descreve que a informação funciona como um componente intrínseco em quase todos os processos de uma organização, e se de algum modo não houver um entendimento a respeito desses processos, as organizações não serão capazes de perceber a relevância de suas fontes de informações e, desse modo, perderão espaço perante o mercado.

O conhecimento, por sua vez, como resultado de dados já transformados em informações em um sistema que se retroalimenta, pois segundo Xavier e Costa (2010, p. 78):

\footnotetext{
A informação e o conhecimento são simultaneamente causa e efeito um de si mesmos, numa interação dinâmica em que a sucessão pode ser plenamente invertida, mas não gera nenhuma contradição, pois se é causa e efeito com relação a coisas diferentes em momentos distintos, quer dizer que se é causa só quando o outro é efeito e se é efeito apenas quando o outro for causa, gera assim expansão benéfica a ambos.
}

A preservação e o uso da informação produzida pelas organizações é uma preocupação antiga dos pesquisadores de Economia e Administração, principalmente nos Estados Unidos. Em 1925, a Universidade de Harvard criou a Business History Society (BHS), uma organização 
que, de uma maneira geral, estimulava estudos microeconômicos em oposição às pesquisas sobre finanças públicas, investimentos de capitais entre outros, muito comuns naqueles momentos. Esse fato contribuiu para o desenvolvimento da business history, espécie de historiografia direcionada ao papel de empresas e empresários no desenvolvimento econômico e social (GOULART, 2005).

A Baker Library era uma das instituições responsáveis por receber documentos e arquivos sobre o surgimento e desenvolvimento empresarial, contendo principalmente acervos da área financeira de empresas. A consequência desse movimento foi o estabelecimento de uma relação entre a preservação de arquivos empresariais e a pesquisa histórica. Contudo, os critérios de avaliação dos acervos adquiridos não preservavam a organicidade das informações, já que naquele momento a pesquisa histórica voltada ao ambiente empresarial era influenciada fortemente pelos interesses dos empresários que financiavam a aquisição desses arquivos pela universidade (GOULART, 2005). Nesse contexto, ainda que a construção desses acervos estivesse relacionada com os interesses dos gestores, a preservação ia de encontro às necessidades de pesquisa acadêmica e não necessariamente à sua utilização como informação estratégica.

Ao longo dos anos, os adeptos da Business History desenvolveram pesquisas voltadas à compreensão dos aspectos organizacionais ligados ao sucesso ou fracasso empresarial em grandes corporações. Além da inegável importância para os estudos econômicos, esses trabalhos contribuíram para a percepção de que a existência de um acervo documental, com informações preservadas seria um ativo importante para as próprias organizações compreenderem as condicionantes de sua trajetória.

Considerando este histórico, fica claro que a informação existente dentro das organizações é um fator determinando para a capacidade de reflexão e tomada de decisão sobre seus os rumos. Porém, não basta existir um acervo documental preservado. É necessário construir um repositório que recolha, interprete e analise informações de diferentes origens, internas ou externas à organização, mas que a ela se refiram.

De acordo com Tarapanoff (2006, p. 23):

A informação é um fator determinante para a melhoria de processos, produtos e serviços, tendo valor estratégico em organizações. A ideia da informação como ferramenta estratégica evoluiu depois que a gestão da informação mudou, de seu foco inicial de gestão de documentos e dados, para recursos informacionais, mostrando resultados em relação à eficiência operacional, evitando desperdício e automatizando processos. A nova visão se espalhou por grandes corporações privadas, que passaram

InCID: R. Ci. Inf. e Doc., Ribeirão Preto, v. 7, n. 1, p. 111-130, mar./ago. 2016. 
Competência em Informação e Cultura Organizacional: fatores fundamentais na construção da memória organizacional

a instituir uma estrutura formal, em geral ligada ao alto escalão hierárquico, para cuidar da gestão dos recursos informacionais.

Ao longo das últimas décadas, houve uma mudança no que diz respeito à gestão documental nas organizações, com o documento cedendo espaço ao seu conteúdo informacional. Do ponto de vista da gestão, defende-se que é mais importante o conhecimento explicitado em um documento que o próprio suporte. Sendo assim o profissional da informação não se limita apenas à organização e classificação dos documentos, devendo realizar uma análise profunda das informações ali contidas.

A memória organizacional se torna, então, uma ferramenta para a gestão da informação e do conhecimento organizacional para que tanto o conhecimento tácito quanto o explícito possam ser armazenados e utilizados futuramente. Segundo Valentim (2008) a informação é considerada um objeto, porque pode ser colocada em um suporte material e a partir de então o conhecimento ali contido é observado por um grupo ou pessoa. A informação é também vista como um fenômeno, uma vez que na elaboração de um documento o indivíduo necessita relacionar, isolar, associar, dissociar, analisar e sintetizar, ou seja, abarca diferentes processos cognitivos para formar o conhecimento explícito em forma de documento.

Bellotto (2004, p. 271) defende que a memória organizacional é

algo que vai muito além do próprio conteúdo do documento. Os conjuntos informacionais que se geram não podem ser definidos compartimentadamente como material de arquivo, de biblioteca ou de centro de documentação, por serem atípicos, como totalidade, a qualquer um deles. Esses conjuntos de dados constituem a memória.

A memória se caracteriza por unir informações e documentos que podem ser orgânicos ou não, ou seja, sua função é referenciadora, garantindo a existência de documentos ordenados em seus lugares para que a informação seja localizada pelo pesquisador. É considerada uma abstração formada por elementos reais. Em suma é a integra de um conjunto de dados a serem trabalhados de modo a adquirirem sentido (BELLOTTO, 2004).

A memória organizacional, segundo Simião (2014), concede respostas às principais questões sobre a organização, seu ambiente, bem como os processos e produtos organizacionais. Isso significa que a memória organizacional envolve o contexto interno e externo, abrangendo os acontecimentos e o meio ao qual esta inserida.

Ressalta-se que é fundamental a diferenciação entre a memória organizacional e a memória institucional, que contempla a memória social do grupo, para construção de relatos 
sobre a evolução global da organização e está relacionada à ideia de legitimidade e à identidade do grupo. Já a memória organizacional está ligada à eficiência da organização, permitindo a existência de modificações em seu percurso. Fica claro, portanto, que ambos os termos diferem em seus objetivos (NASSAR, 2007).

Se considerarmos as três razões principais apontadas por Goulart (2005, p. 15) para a construção da memória institucional, veremos que as duas abordagens se complementam. Inicialmente a celebração de datas, quando a memória é constituída para que a organização conheça a sua trajetória e estabeleça um referencial simbólico relativo à sua trajetória. Em segundo lugar, a utilização do passado organizacional como mecanismo de construção de uma imagem, num sentido ideológico. Por fim, a possibilidade de novos acervos de dados disponíveis como aporte à gestão, onde a história e a cultura organizacional agrupam um conjunto de informações que auxiliam no desenvolvimento das atividades e no crescimento organizacional.

Em todos os casos, considera-se que a memória está relacionada com o futuro, já que a partir dos conhecimentos apropriados como sujeito cognoscente, os indivíduos se reconhecem como seres sociais e constroem seu presente, influenciando em seu futuro. Dessa maneira, o futuro não pode existir sem um passado (MOLINA; VALENTIM, 2011).

$\mathrm{Na}$ perspectiva da gestão do conhecimento, além da dimensão informacional propriamente dita, portanto, a memória organizacional também é influenciada pela cultura organizacional, como fica claro na definição utilizada por Valentim (2004, p.1):

a gestão do conhecimento é um conjunto de estratégias para criar, adquirir, compartilhar e utilizar ativos de conhecimento, bem como estabelecer fluxos que garantam a informação necessária no tempo e formato adequados, a fim de auxiliar na geração de ideias, solução de problemas e tomada de decisão.

Não se pode esquecer da gestão da informação, processo fundamental que lida com as informações armazenadas e organizadas que podem fazer parte da memória, explicada por Valentim (2004, p. 1) como:

A gestão da informação é um conjunto de estratégias que visa identificar as necessidades informacionais, mapear os fluxos formais de informação nos diferentes ambientes da organização, assim como sua coleta, filtragem, análise, organização, armazenagem e disseminação, objetivando apoiar o desenvolvimento das atividades cotidianas e a tomada de decisão no ambiente corporativo.

A memória organizacional torna-se, então, uma ferramenta para a gestão da informação e do conhecimento organizacional para que tanto o conhecimento tácito quanto o explícito possam ser armazenados e utilizados futuramente. Segundo Valentim (2008) a informação é 
Competência em Informação e Cultura Organizacional: fatores fundamentais na construção da memória organizacional

considerada um objeto, porque pode ser colocada em um suporte material e a partir de então o conhecimento ali contido é observado por um grupo ou pessoa. A informação é também vista como um fenômeno, uma vez que na elaboração de um documento o indivíduo necessita relacionar, isolar, associar, dissociar, analisar e sintetizar, ou seja, abarca diferentes processos cognitivos para formar o conhecimento explícito em forma de documento.

No contexto da gestão da informação e do conhecimento, os relatórios internos e os conteúdos para internet e extranet são importantes produtos da memória, já que armazenam informações e conhecimentos sobre inovação, produtos, serviços, estratégias de mercado que são confidenciais. Esses produtos são fonte de pesquisa, permitindo realizar uma busca mais rápida de dados, informações e imagens (TOTINI; GAGETI, 2004).

Este é um processo complexo, especialmente a partir do desenvolvimento dos sistemas de informação, quando os profissionais da informação começaram a se preocupar com a preservação das características dos arquivos digitais, sendo fundamental entender as relações existentes entre as funções administrativas e as características de tipos documentais, a fim de transferir documentos tradicionais para o ambiente virtual e garantir a preservação da informação orgânica em seu contexto de produção e possibilitar efetivamente sua utilização futura (VITORIANO, 2011, p. 87).

Assim, a memória é a capacidade de preservar, armazenar e usar as informações do passado em um momento atual (SASIETA; BEPPLER; PACHECO, 2011, p. web). Para construir uma memória organizacional que atenda as necessidades da organização, o profissional deve possuir uma gama de conhecimentos arquivísticos, computacionais, administrativos, legais, saber como analisar o contexto em que o documento foi produzido e o contexto atual da organização.

Uma vez que o conhecimento produzido nas organizações é explicitado, os indivíduos terão acesso às praticas de sucesso e aos fracassos da organização, facilitando a aprendizagem e consequentemente, atingindo o objetivo da memória organizacional. Não obstante, a busca e o armazenamento de informações e conhecimentos requerem dos gestores o desenvolvimento de competências específicas, especialmente a competência em informação.

\section{Competência em Informação nas organizações}


A competência em informação é conceituada a partir de diferentes interpretações, não existindo um conceito único. Trata-se de um movimento transdisciplinar mundial, que inicialmente estava ligado à sociedade da informação e no contexto prático desenvolveu-se com a atividade bibliotecária. Nas pesquisas atuais, encontram-se estudos associando a competência em informação a áreas como a administração, a política, o jornalismo, entre outras (DUDZIAK, 2008).

No contexto atual, de acordo com Belluzzo (2011), não é suficiente gerenciar de forma efetiva e eficaz o serviço informacional, mas é primordial que o profissional da informação seja capaz de situar-se no centro organizacional para que exista uma transformação e adequação do ambiente, com o objetivo de conhecer os conhecimentos que compõem a organização. A partir da contextualização da organização, o profissional poderá atender as necessidades de informação dos diferentes departamentos, construindo uma memória organizacional eficiente e eficaz.

Assim, é fundamental que o profissional possua características como a receptividade a novas mudanças, enfrentar as dificuldades, compreender a missão, os objetivos e os valores organizacionais e enfrentar os desafios e compromissos de maneira inovadora (BELLUZZO, 2011).

O profissional da informação deve possuir saberes relacionado com sua área de atuação e também, possuir conhecimentos de administração que envolve planejar, organizar, dirigir e coordenar processos. Sendo assim no ambiente das unidades de informação, cabe ao profissional utilizar a tecnologia e os recursos informacionais eficientemente (LIMA, OLIVEIRA, 2010).

É fundamental que o profissional da informação conheça a organização de uma maneira sistêmica e esteja envolvido em diferentes atividades e projetos nos diversos departamentos. Situando-se no centro organizacional, o profissional da informação se apropria e dissemina conhecimentos que serão aplicados na construção da memória organizacional.

No que concerne à função do profissional para construir e atuar na memória organizacional, a autora Bellotto (2004, p. 275) defende que:

[...] Aos olhos do leigo, pode parecer que sua função é rastrear o documento e repetilo. No entanto, quando no exercício correto de sua profissão, sua atitude é acionar os conceitos adquiridos para cumprir sua função de descobrir, apreender, analisar os acontecimentos passados e todo o substrato que jaz entre eles e mais o seu encadeamento para, então, explicitá-los a sociedade do seu tempo [...]. O historiador

InCID: R. Ci. Inf. e Doc., Ribeirão Preto, v. 7, n. 1, p. 111-130, mar./ago. 2016. 
Competência em Informação e Cultura Organizacional: fatores fundamentais na construção da memória organizacional

serve-se do documento como uma ponte para o passado, enquanto ao documentalista interessa rastrear o documento pelos dados nele contidos [...].

A fim de que seja competente em informação, é imprescindível que o profissional da informação adquira habilidades relacionadas com a busca de novos conhecimentos, aprenda com sua experiência, analise e construa documentos que atendam à necessidade de explicitação do conhecimento. Ressalta-se que na organização o documento em si como objeto não é o foco principal da memória organizacional, o mais importante é o conteúdo que ele apresenta.

Além da competência em informação, a cultura organizacional deve ser compreendida como um elemento primordial na manutenção dessa memória, bem como no comportamento e conhecimento das pessoas.

\section{A Cultura Organizacional e seus desdobramentos}

Destaca-se inicialmente que "a cultura é um fenômeno humano e por sua amplitude de implicações, deve ser estudada com o auxílio de mais de um ramo do conhecimento" (CROZATTI, 1998, p. 5). Outro ponto de relevância é que a cultura, em si, possui muitas vertentes, como por exemplo, a sociológica, a antropológica, administrativa, dentre outras.

A cultura organizacional está presente em qualquer tipo de organização, seja ela de pequeno ou grande porte, internalizada de forma objetiva e subjetiva. Seguindo essa mesma linha de discussão Arruda (2006, p. 18) afirma que

A cultura organizacional passa a ser a mente da organização, a crença comum que se reflete nas tradições e nos hábitos, bem como em manifestações mais perceptíveis (histórias, símbolos, ou mesmo edifícios e produtos). A cultura organizacional não existiria sem as pessoas. Neste sentido, ao abordar a cultura é válido mencionar como as pessoas estão estruturadas nas organizações. As cinco partes das organizações seriam: núcleo operacional, cúpula estratégica, linha intermediária, tecno-estrutura e assessoria de apoio.

De forma sintética pode-se descrever a cultura organizacional como sendo o conjunto de pressupostos elencados como essenciais para a vivência em grupo, nos quais devemos prestar atenção, em como devemos reagir (emocionalmente) sobre o que acontecerá e que ações manifestar em vários tipos de situações. Diante disso Schein (2009, p. 17) define cultura organizacional como sendo:

O conjunto de pressupostos básicos que um grupo inventou, descobriu ou desenvolveu ao aprender como lidar com os problemas de adaptação externa e integração interna e que funcionaram bem o suficiente para serem considerados válidos e ensinados a novos membros como a forma correta de perceber, pensar e sentir, em relação a esses problemas. (tradução nossa)

InCID: R. Ci. Inf. e Doc., Ribeirão Preto, v. 7, n. 1, p. 111-130, mar./ago. 2016. 
A cultura organizacional possui elementos que a constituem e influencia os sujeitos no modo como se relacionam, pensam e sentem no ambiente organizacional. Segundo Schein (2009) os principais elementos são: valores, crenças e pressupostos, rituais, cerimônias, heróis, tabus e normas.

Ainda segundo Schein (2009) a cultura organizacional apresenta sete elementos: os valores que reforçam a razão de ser da organização, as crenças e os pressupostos que conduzem os objetivos, os rituais que ocorrem frequentemente nas atividades das pessoas, as cerimônias para reforçar os valores, os heróis utilizados como exemplo, tabus e normas.

Para o autor, estes elementos se articulam como representantes dos diversos níveis de apreensão da cultura organizacional por seus integrantes, representando os mecanismos pelos quais o grupo se reconhece e se autodetermina.

\section{Resultados e discussões}

Com base nas discussões apresentadas anteriormente, construiu-se um quadro a fim de demonstrar a relação entre os elementos da cultura organizacional propostos por Schein (2009) com as habilidades e capacidades, formadoras da competência em informação para o uso da memória organizacional. 
Competência em Informação e Cultura Organizacional: fatores fundamentais na construção da memória organizacional

Quadro 1: Elementos da cultura organizacional, habilidades, capacidades e uso da memória na organização

\begin{tabular}{|c|c|c|}
\hline $\begin{array}{l}\text { Principais elementos da } \\
\text { Cultura Organizacional }\end{array}$ & $\begin{array}{c}\text { Habilidades e Capacidades } \\
\text { (Competência em Informação) }\end{array}$ & $\begin{array}{c}\text { Uso da memória na } \\
\text { organização }\end{array}$ \\
\hline $\begin{array}{l}\text { Valores: ações importantes para a } \\
\text { organização, aquilo que é bem } \\
\text { visto pelos indivíduos, ações } \\
\text { positivas. }\end{array}$ & $\begin{array}{l}\text { Pessoas que procuram aprender } \\
\text { com o próprio trabalho e realizam } \\
\text { cursos de capacitação, } \\
\text { reconhecem que o conhecimento } \\
\text { é fundamental para o crescimento } \\
\text { organizacional, compartilham } \\
\text { conhecimentos e informação. }\end{array}$ & $\begin{array}{l}\text { Valorização do conhecimento } \\
\text { organizacional e estímulo para } \\
\text { compartilhar as informações e } \\
\text { novos conhecimentos. }\end{array}$ \\
\hline $\begin{array}{l}\text { Crenças e Pressupostos: é aquilo } \\
\text { que os indivíduos acreditam } \\
\text { como primordial na organização. }\end{array}$ & $\begin{array}{l}\text { Indivíduo acredita que seu } \\
\text { conhecimento contribui com a } \\
\text { organização, possui um } \\
\text { comportamento aberto, tem } \\
\text { confiança de que seu emprego é } \\
\text { estável porque dissemina as } \\
\text { informações. }\end{array}$ & $\begin{array}{l}\text { Crença de que a memória } \\
\text { organizacional irá contribuir com } \\
\text { o crescimento da organização. }\end{array}$ \\
\hline $\begin{array}{l}\text { Rituais: atividades que se } \\
\text { repetem na rotina de trabalho. }\end{array}$ & $\begin{array}{l}\text { Realiza com } \\
\text { atividades de busciência as acesso, } \\
\text { análise de informações, } \\
\text { diagnostica uma necessidade de } \\
\text { informação em sua área de } \\
\text { atuação. }\end{array}$ & $\begin{array}{l}\text { Lida com a informação de uma } \\
\text { maneira eficaz e eficiente, } \\
\text { pensando em contribuir com a } \\
\text { memória em suas atividades de } \\
\text { rotina. }\end{array}$ \\
\hline $\begin{array}{l}\text { Cerimônias: organização de um } \\
\text { evento na organização para } \\
\text { comunicação. }\end{array}$ & $\begin{array}{l}\text { Os indivíduos se sentem livres } \\
\text { para divulgar as informações e } \\
\text { acontecimentos em seu } \\
\text { departamento, os sucessos e } \\
\text { dificuldades de determinados } \\
\text { procedimentos. }\end{array}$ & $\begin{array}{l}\text { Comunicar as necessidades e } \\
\text { desafios a serem enfrentados, } \\
\text { contribuindo com a preservação } \\
\text { da memória. }\end{array}$ \\
\hline $\begin{array}{l}\text { Heróis: individuo exemplo } \\
\text { baseado no conhecimento, } \\
\text { alguém que salvou a organização } \\
\text { de uma crise. }\end{array}$ & $\begin{array}{l}\text { Os indivíduos irão nortear seus } \\
\text { comportamentos e atitudes } \\
\text { baseados nos heróis. }\end{array}$ & $\begin{array}{l}\text { O herói se relaciona com a } \\
\text { memória organizacional, como } \\
\text { um exemplo a ser seguido. Pode } \\
\text { representar ou não os valores da } \\
\text { organização. }\end{array}$ \\
\hline $\begin{array}{l}\text { Tabus: aquilo que não pode ser } \\
\text { falado ou que não se pode fazer } \\
\text { na organização porque gera } \\
\text { controvérsias. }\end{array}$ & $\begin{array}{l}\text { A pessoa tem o conhecimento de } \\
\text { que o tabu é prejudicial para a } \\
\text { organização e se utiliza de suas } \\
\text { habilidades para evitá-lo. }\end{array}$ & $\begin{array}{l}\text { O tabu pode afetar a memória } \\
\text { organizacional de maneira } \\
\text { negativa e positiva, dependendo } \\
\text { da abordagem que se dê ao } \\
\text { conteúdo informacional. }\end{array}$ \\
\hline $\begin{array}{l}\text { Normas: são as regras } \\
\text { organizacionais, } \\
\text { comportamentos que devem ser } \\
\text { obedecidos por diferentes razões. }\end{array}$ & $\begin{array}{l}\text { O indivíduo adéqua seu modo de } \\
\text { trabalho às normas pré- } \\
\text { estabelecidas, possui o modo de } \\
\text { pensar e se comporta baseando-se } \\
\text { nas regras. }\end{array}$ & $\begin{array}{l}\text { Podem contribuir com a } \\
\text { organização } \\
\text { funcionamento da memória } \\
\text { organizacional. Por outro lado, } \\
\text { pode impor barreiras e } \\
\text { dificuldades à memória. }\end{array}$ \\
\hline
\end{tabular}

Fonte: Elaborado pelos autores

Desse modo, é fundamental que os valores da organização estejam voltados para o aprendizado, de modo a estimular os indivíduos a realizarem cursos de capacitação e atualizar seus conhecimentos técnicos. Além disso, vale ressaltar a valorização de uma cultura de compartilhamento de informações e conhecimentos com os demais para fortalecer o grupo. $\mathrm{O}$

InCID: R. Ci. Inf. e Doc., Ribeirão Preto, v. 7, n. 1, p. 111-130, mar./ago. 2016. 
Selma Letícia Capinzaiki Ottonicar, Luis Fernando Condutta e Marcia Cristina de Carvalho Pazin Vitoriano

gestor pode aplicar recompensas àqueles que contribuem com o acervo da memória organizacional e o utiliza para estimular a criatividade, a inovação e a tomada de decisão.

As crenças e os pressupostos devem estar alinhados com os valores organizacionais para que os indivíduos acreditem e incorporem em seu comportamento o compartilhamento de informações e conhecimentos e, principalmente, ter a certeza de que não será demitido por dividir suas experiências e saberes. Isso fará com que haja uma maior movimentação de documentos da memória.

Os rituais são as ações de busca, acesso e análise das informações que ocorrem nas atividades diárias, permitindo que os documentos disponíveis sejam revistos e questionados para melhorar seu conteúdo no processo de uso. As cerimônias são eventos que podem servir para reforçar os valores, as crenças, os pressupostos e os rituais; é um momento em que o grupo vê o resultado de seus esforços.

O herói é geralmente representado por um líder que obteve sucesso em adotar o aprendizado ao longo da vida como objetivo e usa a memória organizacional frequentemente. Já os tabus servem para demonstrar que determinadas ações ou acontecimentos devem ser evitados pelos indivíduos e estão associados a uma estória de insucesso ou desobediência na organização. Afetam a memória de uma maneira negativa por exemplificar situações desagradáveis e ao mesmo tempo, podem ser positivos se forem adequadamente tratados do ponto de vista informacional, porque os indivíduos irão evitá-los.

Além de existir normas formais sobre o trabalho específico de cada cargo é interessante desenvolver normas voltadas ao uso consciente e ético da informação e do conhecimento, permitindo desfrutar da memória organizacional de uma maneira adequada. A formalização desse tipo de norma representa a importância da competência em informação e da memória para o crescimento da organização. 
Competência em Informação e Cultura Organizacional: fatores fundamentais na construção da memória organizacional

\section{Considerações finais}

A construção da memória organizacional é uma operação bastante complexa, que deve ocorrer atendendo aos requisitos dos gestores e ser adequada às reais necessidades organizacionais. Muitas vezes, documentos selecionados para retratar uma boa imagem ao público não são suficientes na gestão da informação e do conhecimento organizacional. Seu desenvolvimento deve estar baseado num tripé composto pela adequada seleção de documentos e informações que a comporão; no desenvolvimento de competência em informação tanto pelo profissional da informação quanto pelos gestores empresariais e na construção de uma cultura que valorize a informação e o conhecimento como pressuposto organizacional.

As informações sobre os produtos, processos e serviços realizados não são suficientes para contribuir com o aprendizado organizacional. É importante a presença de informações e conhecimentos sobre projetos ineficientes, que possam ser analisados, de modo a impedir que os indivíduos cometam os mesmos erros, ganhando tempo nas operações.

Da mesma forma as informações e conhecimentos são elementos fundamentais para que os indivíduos possuam a competência em informação e se utilizem das habilidades e capacidades adquiridas ao longo da experiência de trabalho. Realizar cursos para se atualizar, treinamentos para adquirir conhecimentos específicos de sua área e as próprias atividades rotineiras são elementos que contribuem com o desenvolvimento da competência em informação. Diante dessas breves constatações defende-se que os elementos culturais podem interferir na construção da memória organizacional e na valorização da competência em informação, fator fundamental para o uso dessa memória.

Portanto, para criar uma memória que atenda aos requisitos da organização o profissional responsável deve ser competente em informação, buscando aprimorar suas habilidades e conhecimentos ao longo da vida. Em suma, o profissional da informação deve possuir as seguintes habilidades e capacidades:

- Estruturação de informações e dados;

- Análise de conteúdo documental;

- Compreender as necessidades organizacionais;

- Observar o contexto passado e atual;

- Conhecimento de leis;

- Visão sistêmica da organização;

InCID: R. Ci. Inf. e Doc., Ribeirão Preto, v. 7, n. 1, p. 111-130, mar./ago. 2016. 
Selma Letícia Capinzaiki Ottonicar, Luis Fernando Condutta e Marcia Cristina de Carvalho Pazin Vitoriano

- Facilidade em lidar com pessoas;

- Formular uma imagem positiva da organização;

- Remontar a história organizacional;

- Armazenar informações de interesse à comunidade;

- Conhecer sobre gestão de informação e conhecimento;

- Conhecer os processos técnicos, operacionais e administrativos;

- Conhecer os sistemas de informação;

- Estabelecer critérios de relevância para documentos e informações;

- Se adequar à falta de espaço;

- Evitar a perda de documentos e informações importantes;

- Armazenar processos eficazes e ineficazes;

- Facilitar a busca de informações para os membros da organização.

Sendo assim, a competência em informação contribui com a construção da memória organizacional, uma vez que os profissionais devem possuir habilidades, capacidades e conhecimentos na criação de uma memória organizacional eficiente e eficaz. Da mesma forma, a cultura organizacional influencia o modo como esse processo se dará.

A combinação desses elementos-chave permite que as organizações aprendam com seus erros e acertos. Assim, todos os sujeitos de certo modo emitem influências sobre a constituição e desenvolvimento da memória organizacional.

Não obstante, membros que possuam competência em informação valorizam a memória organizacional como um recurso de aprendizado que colabora com o desenvolvimento de novos projetos, produtos, processos, serviços e ainda contribui com a formação da ideologia organizacional e da história da cultura material, criando uma imagem positiva da empresa perante a sociedade.

InCID: R. Ci. Inf. e Doc., Ribeirão Preto, v. 7, n. 1, p. 111-130, mar./ago. 2016. 
Competência em Informação e Cultura Organizacional: fatores fundamentais na construção da memória organizacional

\section{Referências}

ARRUDA, M. F. de. Cultura Organizacional e Inovação: estudo de caso em um hospital privado com características de inovação no município de São Paulo. 2006. Dissertação (Mestrado) - Escola de Administração de Empresas de São Paulo da Fundação Getúlio Vargas, FGV, São Paulo, 2006.

BELLOTTO, H. L. Arquivos permanentes: tratamento documental. 2. ed. Rio de Janeiro: FGV, 2004.

BELLUZZO, R. C. B. As competências do profissional da informação nas organizações contemporâneas. Revista Brasileira de Biblioteconomia e Documentação, São Paulo, v. 7, n. 1, p. 58-73, nova série, jan/jun. 2011.

CAPURRO, R.; HJORLAND, B. O Conceito de informação. Perspectivas em Ciência da Informação, Belo Horizonte, v. 12, n. 1, jan./abr. p. 148-207, 2007.

CHOO, C. W. A organização do conhecimento: como as organizações usam a informação para criar significado, construir conhecimento e tomar decisões. 3. ed. São Paulo: SENAC, 2011.

CROZATTI, J. Modelo de gestão e cultura organizacional: conceitos e interações. Caderno de Estudos, São Paulo, FIPECAFI, v.10, n. 18, maio/ago. 1998.

DAVENPORT, T. H. Ecologia da informação. São Paulo: Futura, 1998.

DRUCKER, P. F. Administrando para o futuro: os anos 90 e a virada do século. 5. ed. São Paulo: Pioneira, 1998.

DUDZIAK, E. A. Os faróis da sociedade de informação: uma análise crítica sobre a situação da competência em informação no Brasil. Informação \& Sociedade, João Pessoa, v. 18, n. 12, p. 41-53, maio/ago. 2008.

EISENBERG, M. B. Information literacy: essencial skills for the information age. Journal of library and information technology, p. 39-47, 2008.

FARIA, et al. Competências do profissional da informação: uma reflexão a partir da Classificação Brasileira de Ocupações. Ciência da Informação, Brasília, v. 34, n. 2, p. 26-33, maio/ago. 2005. 〈Disponível em: http://revista.ibict.br/index.php/ciinf/article/view/647>

Acesso em: 10 mar. 2016.

GIL, A. C. Métodos e técnicas da pesquisa social. 6.ed. São Paulo: Atlas, 2008.

GOULART, S. Patrimônio documental e história institucional. São Paulo: Associação de Arquivistas de São Paulo, 2005.

LIMA, E. S.; OLIVEIRA, I. G. S. C. O bibliotecário e as competências administrativas: uma revisão de literatura sobre a construção de um novo perfil. In: 
ENCONTRO NACIONAL DE ESTUDANTES DE BIBLIOTECONOMIA, DOCUMENTAÇÃO, GESTÃO, E CIÊNCIA DA INFORMAÇÃO, 33.,2010, João Pessoa. Anais... João Pessoa: Universidade Federal da Paraíba, 2010. p.168-176.

LOGAN, R. K. O que é informação?: a propagação da organização na biosfera, na simbolosfera, na tecnosfera e na econosfera. Rio de Janeiro: contraponto: PUC-Rio, 2012.

MARCONI, M. A.; LAKATOS, E. M. Técnicas de pesquisa: planejamento e execução de pesquisas, amostragens e técnicas de pesquisa, elaboração, análise e interpretação dos dados. São Paulo: Atlas, 2006.

MENEZES, E. M. Estruturação da memória organizacional de uma instituição em iminência de evasão de especialistas: um estudo de caso na COHAB. 2006. Dissertação (Mestrado) - Programa de Pós-Graduação em Gestão do Conhecimento e Tecnologia da Informação, Universidade Católica de Brasília, Brasília, 2006.

MOLINA, L. G.; VALENTIM, M. L. P. Memória organizacional, memória corporativa e memória institucional: discussões conceituais e terminológicas. Revista EDICIC, v. 1, n. 1, p. 262-276, jan./mar. 2011. Disponível em: 〈http://www.edicic.org/revista〉. Acesso em: 09 fev. 2015.

NASSAR, P. A mãe de todas as responsabilidades. Terra Magazine, São Paulo, 18 ago. 2007. Disponível em: <http://terramagazine.terra.com.br/interna/0,,OI1837029-EI6786,00A+mae+de+todas+as+responsabilidades.html>. Acesso em: 03 out. 2014.

SASIETA, H. A. M.; BEPPLER, F. D.; PACHECO, R. C. S. A memória organizacional no contexto da engenharia do conhecimento. Datagramazero, v. 12, n. 3, ago. 2011. Disponível em: 〈http://www.dgz.org.br/ago11/Art_06.htm>. Acesso em 06 fev. 2015.

SCHEIN, E. H. Cultura organizacional e liderança. São Paulo: Atlas, 2009.

SETZER, V. W. Dado, informação, conhecimento e competência. In: Os Meios Eletrônicos e a Educação: Uma Visão alternativa. São Paulo: Editora Escrituras, Coleção Ensaios Transversais Vol. 10, 2001. Disponível em: < https://www.ime.usp.br/ vwsetzer/dadoinfo.html>. Acesso em: 09 mar. 2016.

SIMIÃO, H. E. Memória organizacional. Bate Byte, c2009. Disponível em: <www.batebyte.pr.gov.br/modules/conteudo/conteudo.php?conteudo=1716>. Acesso em: 03 out. 2014.

TARAPANOFF, K. (Org.). Inteligência, informação e conhecimento. Brasília: IBICT, UNESCO, 2006.

TOTINI, B; GAGETI, E. Memória de empresa: história e comunicação de mãos dadas, a construir o futuro das organizações. São Paulo: Aberje, 2004.

VALENTIM, M. L. P. (Org.). Gestão da informação e do conhecimento no âmbito da Ciência da Informação. São Paulo: Polis: Cultura acadêmica, 2008. 
VALENTIM, M. L. P. Gestão da informação e gestão do conhecimento: especificidades e convergências. Infohome, nov. 2004. Disponível em:

<http://www.ofaj.com.br/colunas_conteudo.php?cod=88>. Acesso em: 15 jun. 2015.

VITORIANO, M. C. C. P. Obrigação, controle e memória: aspectos legais, técnicos e culturais da produção documental de organizações privadas. 2011. Tese (Doutorado em História Social) - Faculdade de Filosofia, Letras e Ciências Humanas, Universidade de São Paulo, São Paulo, 2012. Disponível em:

<http://www.teses.usp.br/teses/disponiveis/8/8138/tde-22082012-090854/>. Acesso em: 22 set. 2014.

XAVIER, R.; COSTA, R. Relações mútuas entre informação e conhecimento: o mesmo conceito? Ciência da Informação, Brasília, v. 39, n. 2, p. 75-83, 2010. 